\title{
DANZA COMO LENGUAJE; DANZA COMO EXPRESIÓN: ALGUNAS CONSIDERACIONES TEÓRICAS
}

\section{Por Alberto Dallal}

En la danza culmina el cuerpo no (como se ha creído) el movimiento del cuerpo. Esta hipótesis se relaciona analógicamente con la separación y la coexistencia simultáneas, en la mente humąna, de un pensamiento dirigido y uno no dirigido, un pensamiento que se origina y mueve dentro de un esquema lógico y otro que no lo hace así. 1 En este sentido, el presente trabajo intenta "ver" a la danza 1) como el producto superior del cuerpo, como la manifestación "hecha", acabada no sólo de un grupo culturalmente configurado sino de cualquier individuo normal, y 2) como la sencilla expresión de una capacidad o un instinto, expresión que tradicionalmente se realiza por medio del movimiento. Para iniciar una reflexión de esta índole será necesario plantear tres puntos analíticos fundamentales:

$A$. La danza es un lenguaje (el lenguaje más alto y desarrollado del cuerpo) $\mathrm{y}$, por tanto, es en sí misma un conjunto de signos: un código.

B. La "materia prima" (de elemento primario, fundamental; y de elemento primario, original, "a partir del cual...") de la danza es el cuerpo; por tanto, la existencia de la danza se satisface en la existencia del elemento "cuerpo humano".

C. El código consciente, "arreglado", culturalmente desarrollado, supraestructural que muestra la danza actual se relaciona directamente con el movimiento; este código "cultural" ha coexistido con el código (o esquema) forjado ancestralmente por el cuerpo del hombre. En ambos códigos (y a través del tiempo) el movimiento o, mejor dicho, la capacidad de movimiento del cuerpo del hombre ha sido tan sólo un auxiliar del lenguaje "danza".

1 Véase, como introducción al tema, C. G. Jung, pp. 31-58, capitulo titulado, pre cisamente: "Dos formas de pensamiento". 


\section{A. La danza como lenguaje}

\section{Expresión y lenguaje}

No debemos olvidar que los estudios realizados en torno a la danza han considerado a ésta como expresión lograda de grupos y pueblos culturalmente configurados. En efecto, en el análisis de las danzas rituales y autóctonas, incluso en lo que se refiere a sus manifestaciones más primitivas, se da por sentado que la danza era una actividad socialmente organizada, es decir, vinculada a actividades que apoyaban costumbres, acciones y hábitos, o bien actividad sistemática y paralela a las formas más o menos desarrolladas del trabajo del hombre. ${ }^{2}$ En este sentido, el estudio e interpretación de los especialistas en torno a las danzas primitivas se realiza a partir de la danza como expresión de formas de vida estructuradas, o sea, en términos de la creatividad formal propia de las necesidades o impulso del grupo. ${ }^{3} \mathrm{La}$ danza es un fenómeno "alcanzado", dueño de fases y etapas sobrepuestas. Inherentes a ella se señalan acontecimientos "poseedores" de historia, localizables. Como sucede en el ámbito de otras expresiones artísticas, sociales, culturales, la danza, desde esta perspectiva, es un corpus armónico que se desarrolla a partir de un sentido esencial que le da vida, que la obliga a ser dentro de los parámetros que establecen otras actividades y prácticas anteriores y/o simultáneas a ella. Esta circunstancia "organiza" tanto los movimientos corporales 4 como los diseños que los grupos realizan durante la actividad. 5

Este planteamiento historicista de la actividad danza implícitamente niega (se enfrenta a) otra noción teórica del hacer dancístico: la danza como lenguaje. La distancia que existe entre el lenguaje y la expresión delimita ejes cualitativos (nunca cuantitativos) para el examen meto-

2 "... [en el movimiento rítmico] no hay todavfa arte en el sentido habitual del término. Pero el arte queda incluido en este concepto ya que significa la recreación rie las cosas que se ven y se escuchan, el otorgamiento de forma y sustancia a las percepciones intangibles e irracionales de la semiconciencia, y la experiencia del proceso creativo en el éxtasis divino de otro mundo y del olvido del yo. Tan temprano como la Edad de Piedra, la danza se hace obras de arte; y en los umbrales de la Edad de los Metales, la leyenda se apodera de la danza y la eleva al plano del drama."

Curt Sachs, p. 6.

3 Curt Sachs, p. 199.

4 Curt Sachs, pp. 24-48.

3 Curt Sachs, pp. 139-173. 
cológico de un objeto de estudio dado. Esquemáticamente, las diferencias que plantean el lenguaje y la expresión se enumerarían de la siguiente manera:

\section{LENGUA JE}

Comunicación primaria entre dos elementos primarios, posiblemente desconocidos

Sintesis

Signos

Aspectos teóricos

Sentido único:

abstracción

Esquemas

Materialización

Medición de posibilidades

Producto único

... etcétera
EXPRESIÓN

Comunicación organizada entre dos o más conjuntos localizables

Descripción

Símbolos

Aspectos históricos

Sentidos:

tantos como objetivos concretos se descubran

Temas

Idealización

Medición de logros

Productos múltiples

... etcétera

En las consideraciones que fundamentan a la noción "danza como lenguaje", el tiempo y el espacio, por ejemplo, existen como categorías adjudicables al fenómeno, como unidades implícitas a la experiencia. Sin embargo, las teorizaciones sobre los elementos vinculados a la "danza como expresión" no fueron "extraídos" de la actividad misma, sino "anexados" durante el proceso de experimentación. Mary Wigman frente al espejo; Mary Wigman discutiendo con Von Laban; Mary Wigman en plena reflexión, descubrió (e impuso más tarde como categorías) las relaciones del cuerpo con el espacio. $O$ sea: aun en la danza de hoy los conceptos son elementos auxiliares que conducen al objeto de estudio. Este procesamiento consciente de los elementos resulta natural por la innata tendencia de la mente a "aislar" su objeto de estudio para explicarlo. ${ }^{-}$Es decir, para el análisis que se apoya en la noción "danza

B "Todo lenguaje en cuanto tal, es 'representación'; es exposición de una determinada significación mediante un 'signo' sensible." Ernst Cassirer, p. 72. 
como expresión", el tiempo y el espacio, si bien elementos externos y auxiliares, devienen asimismo localizaciones concretas, situaciones objetivas. Con todo, resulta importante considerar en todo momento que el sistema (conjunto dialéctico de interacciones entre signos de una misma naturaleza y/o especie) al que alude la "danza como lenguaje" debe reconocerce tan logrado, tan detectable y accesible como aquel sistema (o conjunto de sistemas) al que se han referido casi todos los estudios de la "danza como expresión". Este último sistema sólo será mencionado, a partir de este momento, para sugerir analoglas que propicien la comprensión cabal del primer sistema.

\section{El lenguaje discursizo}

La trascendencia de los símbolos inventados y organizados por el hombre primitivo al través del lenguaje discursivo no está aún bien explicada. Se han hecho estudios en torno a la singularidad del "acontecimiento" que significa o representa la aparición del lenguaje discursivo, primero como un conjunto de signos y de símbolos: una simbología. Más tarde se considera que la organización de los elementos del lenguaje discursivo, gracias a su operatividad, condujo a una codificación secular y convencional aplicable a las necesidades cotidianas e inmediatas del grupo. Tal vez en el fondo de esta trascendencia (y dictadura o monopolio) del lenguaje discursivo se encuentren, entre otras características, el surgimiento de la palabra-pensamiento, su funcionalidad práctica, sus posibilidades de abstracción, sus instantáneas configuración y comunicabilidad, su facilidad de registro (tanto por el oyente o receptor como por los grupos humanos con relación a otros), etcétera. Sin embargo, podemos asegurar que la naturaleza misma del lenguaje discursivo no puede ser, en estricto sentido lógico, sino el reflejo de un conjunto de características y mecanismos propios de la naturaleza de los procesos mentales del ser humano: sus procesos cerebrales y sus ramificaciones en todo el cuerpo. ${ }^{7}$

7 "La escritura humana refleja a la del universo, es su traducción, pero asimismo su metáfora: dice algo totalmente distinto y dice lo mismo. En la punta de la convergencia el juego de las semejanzas y las diferencias se anula para que resplandezca, sola, la identidad." (Octavio Paz, p. 135. “... un raciocinio muy intenso se desarrolla en forma más o menos hablada, es decir, como si se lo quisiera exponer, enseñar o convencer de él a alguien. Es evidente que se dirige hacia afuera. En este sentido, 
La acción lógica de nombrar las cosas, los objetos, las experiencias para representarlas en la mente, para asirlas simbólicamente, para dominarlas técnicamente, para asumirlas, para conformarlas y hacerlas materia de retención, análisis y manipulación resulta espontáneo para el conjunto de características y aptitudes biológicas de los seres humanos aun en el estadio más bajo de su evolución. Por otra parte, la asignación de un significado o una significación no podrfa considerarse sino una función propia de la "particularización" que toda experiencia humana intenta y/o logra realizar para diferenciarse del resto de la naturaleza. Por ejemplo, la "carga" o hálito poético puede percibirse y explicarse asimismo en las artes visuales, en la música y aun en los sistemas de movimiento y secuencias utilizadas por el cinematógrafo y la danza. En este tren de ideas, podemos estar seguros de que la imposición del lenguaje discursivo, como vía más expedita y práctica para alcanzar y registrar el conocimiento, fue en el hombre una experiencia unívoca, una selección espontánea y natural dentro de un conjunto de posibles vías o sistemas. Las vías no utilizadas y sus distintas combinaciones aparecerían más tarde, con otras posibilidades de desarrollo y codificación, en las múltiples manifestaciones artísticas que, establecidas históricamente, conoce el hombre contemporáneo.

\section{El lenguaje de la danza}

De los lenguajes establecidos o inventados por el hombre hasta la fecha, la danza es el que más directa y naturalmente se vincula al lenguaje discursivo. Al principio, el ademán, la mímica, la gesticulación, el gesto, etcétera, se hallan en el origen mismo del sonido gutural. ${ }^{8}$

Se habla de la danza como de "la madre de las artes" (Sachs) o del arte más antiguo o más nuevo porque su separación del lenguaje discursivo se lleva a cabo con la creación de un sistema específico de símbolos, sistema que probablemente es anterior a los de las otras artes. A dife-

e! pensamiento dirigido o lógico es un pensamiento acerca de la realidad, es decir, que se adapta a la realidad en el cual, expresándolo con otras palabras, imitamos la sucesión de las cosas objetivas y reales, de suerte que las imágenes desfilan en nuestra mente en la misma serie estrictamente causal que los acontecimientos exteriores. También se lo suele llamar pensamiento con atención dirigida." C. G. Jung, pp. 35-36.

8 Ernst Cassirer, pp. 142-143. 
rencia del lenguaje discursivo, que culmina con el código o sistema más operativo y perfecto para el conocimiento y la comunicación cultural del grupo ${ }^{9}$ (el pensamiento dirigido ${ }^{10}$ ), la danza se desprende de la inmovilidad propia del cuerpo hacia una actividad especifica que la realidad objetiva induce al hombre a realizar. ${ }^{11} \mathrm{O}$ sea, mientras el len. guaje discursivo sigue siendo reflejo de los fenómenos que sobrevienen en la realidad (y se convierte en explicación o descripción de ellos) la danza puede considerarse prolongación del instinto, o bien acción transformadora que se incorpora o se añade a un fenómeno específico. Sin embargo, la realización plena de este "desprendimiento hacia la realidad misma" (cuyo impulso, como el del lenguaje discursivo, resulta asimismo producto de una necesidad) no logra establecer sucesivas etapas culturales $\mathrm{y} / \mathrm{o}$ antropológicas que indiquen la evolución histórica humana por medio de los movimientos del cuerpo, tal como los distintos códigos del lenguaje discursivo lo establecen. Es decir, ya sea a causa de su "suncionalidad transformadora" o de su "operatividad" otra, sobreviene un momento histórico específico en que se pierde la posibilidad de una codificación dancística directa, no artística, una situación en que el hombre no "aprovecha" (como lo hará ya muy tarde y sólo asumiéndola como "expresión") los medios lingüísticos que le ofrecían su cuerpo y los movimientos de éste. Si dentro de los parámetros del lenguaje discursivo, el logos sobreviene y va estableciéndose a partir y al través de la unión palabras-significación, el "lenguaje" del movimiento del ente (descle la inmovilidad) no logra la intervención organizadora de sus signos para configurar su código y un "conocimiento" (aprehensión y explicación sistemáticas del mundo) para establecer el logos correspondiente. Tal parece que el logos tradicional, el que se crea y recrea al través del lenguaje discursivo, será el eje del desenvolvimiento civilizador, el que desde fuera impondrá a la relación dialéctica inmovilidadmovimiento toda significación posible. En otras palabras, la utilización y aplicabilidad de la danza como lenguaje universal comunicable jamás

9 "El lenguaje es el catálogo del saber heredado, la crónica de las conquistas nacionales, el área donde se guardan todas las adquisiciones logradas por el genio de los individuos. El sistema de 'modelos' sociales formado de este modo, refleja los procesos de juicio de la raza; y a su vez se convierte en semillero del juicio de las nuevas generaciones." James Mark Baldwin, Thought and things. Anotado por C. G. Jung, p. 39.

10 C. G. Jung, pp. 35-36.

11 "La danza exige totalidad, unicidad, todo en el momento de un cambio que va de lo móvil-inexpresivo hacia lo inmóvil-expresivo." Alberto Dallal, p. 95. 
sobrevendrá en torno a sus posibilidades para alcanzar una adecuada codificación de signos, sino en torno a un conjunto de símbolos impuestos al través del pensamiento, sea éste mítico, ritual, religioso o lógicocientífico. En síntesis: la perdurabilidad y trascendencia de la danza se manifiesta en la historia de la especie humana como una expresión y no como un lenguaje.

¿Cuándo y en qué circunstancias sobreviene la pérdida de esta posibilidad? Nadie puede decirlo todavía. En este sentido, en el conjunto de las manifestaciones artísticas tradicionales, tal vez la música proporcione materiales suficientes para seguir el rastro de sus propias cualidades y capacidades y para alcanzar la "codificación", ya que de alguna manera en la experiencia musical, sentido, estructura y forma configuran un todo, una unidad básica: se objetivan (se hacen objeto de experiencia y/o de estudio) precisamente en una sola "emisión". Las artes visuales pueden, en su estrecha vinculación con los signos del lenguaje discursivo (las palabras: sus formas), considerarse hermanas de éste. Pero no deja de sorprender que los elementos constitutivos de la danza (impulso, fuerza, inmovilidad, movimiento, espacio, ritmo, músculos, diseños) no impusieran desde el principio un cúmulo de operativos diseños "codificables", ciertas cualidades que fueran susceptibles de alcanzar una adecuada sistematización para lograr el establecimiento de una comunicación y un "conocimiento" distintos de la Iógica del lenguaje discursivo.

\section{B. El cuerpo como lenguaje}

\section{Signos y autoconciencia en el cuerpo humano}

La operatividad del lenguaje discursivo para el análisis, el registro, el crdenamiento y la explicación de los fenómenos que ocurren en la realidad ha llevado al hombre a considerarlo elemento fundamental en el desarrollo de su inteligencia. No pocos autores afirman que es el lenguaje discursivo el que nos permite pensar. Es decir, el proceso mental propiamente dicho que ocurre en el cerebro del hombre representa un "decirse a sí mismo las cosas", indica una transformación en lenguaje de las impresiones que la realidad produce y hace penetrar a través de los sentidos. Sea esto cierto, o bien se trate de un proceso complementario del vastísimo fenómeno "inteligencia" (por una parte, esta teoría no 
está confirmada cientificamente; por la otra, no se descarta la posible inclusión en el término "inteligencia" de fenómenos tales como sensibilidad, imaginación, percepciones primarias o elementales, instintos, etcétera), el lenguaje discursivo converge espontánea o inducidamente hacia un proceso psíquico-intelectual que podemos denominar autoconciencia. Sería imposible tratar en unas cuantas páginas los alcances y aspectos filosóficos, psicoanalíticos, fisiológicos y sociológicos del problema. Nos limitaremos a indicar que el proceso de autoconciencia se refiere, en términos generales, al conocimiento que de sí mismo tiene un ente organizado, conocedor y practicante de un sistema o de un conjunto de códigos.

Durante el desarrollo de la "danza como expresión", el proceso de autoconocimiento representa un fenómeno histórico y sociológico. En última instancia, netamente artístico. Las actividades dancísticas de los pueblos primitivos (rituales, guerreras, agrícolas, etcétera) implicaban, además de la práctica metódica (social) o impuesta (religiosa), una acción de acercamiento a las peculiaridades culturales del grupo. En efecto, a través de las danzas rituales los grupos registraban las singularidades de su religión, de sus costumbres e incluso de su raza. Sin embargo, este registro, que cambiaba sólo imperceptiblemente de generación en generación, funcionaba más bien como acción repetitiva, como salvaguarda de una tradición (acumulación de valores sociales y culturáles) que iba configurándose a lo largo del desarrollo del grupo.

Al quedar inmersa en los demás aspectos de la cultura de un grupo determinado, la danza sólo proporcionaba elementos para el autoconocimiento ritual, sociológico, supraestructural de las comunidades. Tal sería la aportación de, por ejemplo, las danzas populares contemporáneas, a través de las cuales nos es posible penetrar en las características culturales de las naciones, no obstante sus numerosas mezclas o sus tendencias universalizadoras. Es decir, este autoconocimiento que los distintos paises del mundo pueden adquirir en torno a las peculiaridades de sus respectivas danzas, sugiere un acercamiento a la supraestructura social, o sea al conjunto de elementos simbólicos o expresivos que configuran una cultura determinada.

¿En dónde radica entonces el punto de inflexión, el punto en que la "autoconciencia" del cuerpo se hace expresión? La autoconciencia del cuerpo establece parámetros internos. La codificación de sus elementos permanece al acecho de los fenómenos (anatómicos, fisiológicos, 
simbióticos, etcétera) que le permitan especificar ciertos signos esenciales. Estos signos forman un conjunto o sistema que propicia autoconocimiento o autocomplacencia: una especie de caudal que se halla siempre "en disposición" de reaccionar, o, más bien, de accionar hacia la realidad y convertirse (ahora sí) en expresión o actividad. Por ejemplo, quien posee un cuerpo bello puede saber o no (internamente) cuáles son las características naturales de su configuración anatómica, las proporciones de sus miembros, etcétera. Sin embargo, si va a ser uso de su cuerpo en situaciones preparadas $u$ organizadas para ello (verbigracia, posar como modelo, hacer un deporte, iniciar una danza, hacer el amor, etcétera), su "autoconciencia" o sistema de conocimientos intervendrá en la acción y los resultados de ella dependerán en gran medida de este sistema. La acción de este individuo sobre la realidad podrá devenir espontánea, natural (como, digamos, se produce la risa de un bebé ante una situación gratificante) o bien "expandir" cierto tipo de elementos que internamente se han "autopreparado" para intervenir ordenada, organizadamente en el fenómeno o situación. A difesencia de lo que plantea la necesaria preparación técnica del bailarín, del deportista, del o la modelo, el autoconocimiento de las características, procesos y signos interiores del cuerpo humano representa un proceso aún no especificado científicamente y hasta la fecha desvinculado casi totalmente del lenguaje discursivo. Se ha dejado al instinto sexual, al impulso narcisista, a la respuesta social espontánea la preparación de este autoconocimiento de los signos corporales. ${ }^{12}$ Hasta ahora, el autoconocimiento del cuerpo es un bien individual sólo aplicable (y explicable) en términos de acción-que-termina-en-un-acto. Sólo es posible ${ }^{13}$ determinar la existencia de esta codificación mediante productos acabados, como "consecuencias", y ello con la condición de que se determinen manifestaciones accesibles al "discernimiento", es decir, que los productos sean clasificables.

12 Por ello el gran "rompimiento" de Isadora Duncan con la danza clásica, así como la tendencia de algunas de las innovadoras de la danza actual (principalmente Mary Wigman), significó una búsqueda inconsciente del código corporal interno, no obstante que ello fuere encauzado de nueva cuenta a las formas expresivas y no al lenguaje corporal.

$13 \mathrm{Y}$, tal vez, sólo es permisible la incorporación de este autoconocimiento a través de un sistema determinado de símbolos, ya sea un conjunto de símbolos morales, sociales $o$ artísticos. 


\section{Gesto, gesticulación}

El gesto y la gesticulación son actos superficiales de un dispositivo interno. El dispositivo obedece a un sistema de impulsos que permanece unido a la realidad mediante una interrelación de acciones y reacciones espontáneas $\mathrm{y} / \mathrm{o}$ inducidas. El gesto y la gesticulación completan la acción reveladora de la palabra $y$, como ella, descubren, más que una idea, una imagen. ${ }^{14}$ De la misma manera que el lenguaje discursivo manifiesta, muestra sólo una parte de la realidad de la "cosa dicha" (un iceberg representaría perfectamente este concepto), el gesto y la gesticulación constituyen una mínima parte de la significación interna del que hace gestos, del que gesticula. Sensaciones, sentimientos, nociones, percepciones, ideas se mezclan en el interior del cuerpo, de la mente; el gesto y la gesticulación implementan ya sea el afán, ya sea la capacidad de "expresión" de un individuo. Por su espontaneidad, por su natural inclusión en las formas utilizadas por el hombre para comunicarse, el gesto, según algunos teóricos, es el embrión de la danza. Para Susan $\mathrm{K}$. Langer:

E1 gesto es el movimiento vital; para quien lo ejecuta es conocido con toda precisión como una experiencia quinética, es decir, como una acción, y un poco más vagamente por la vista como un efecto. Para otros, aparece como un movimiento visible, pero no un movimiento de cosas, que se deslizan, ondulan o ruedan de aquí para allá; es visto $y$ entendido como movimiento vital. Así que siempre es, al mismo tiempo, subjetivo y objetivo, personal y público, querido (o evocado) y percibido. ${ }^{15}$

A pesar de que no se concede esta propiedad a la gesticulación, "el gesto es la abstracción básica mediante la cual se organiza y se crea la ilusión de la danza". ${ }^{16}$ La investigadora concede al gesto, en este senticio, las mismas cualidades de espontaneidad y de expresión, a pesar dc que puede ser "expresivo" o "autoexpresivo", 17 ya que, "puesto que pueden ser controlados conscientemente, los gestos también pueden

14 "El lenguaje discursivo encierra un sentido que para él mismo permanece oculto y que sólo puede descifrar a través de la imagen y la metáfora." Ernst Cassirer, p. 68.

15 Susan K. Langer, p. 164.

16 Susan K. Langer, p. 164.

17 Susan K. Langer, p. 169. 
ser elaborados, igual que los sonidos vocales, en un sistema de simbolos asignados y combinables, un lenguaje discursivo genuino". ${ }^{18}$ Es decir, el gesto no sólo es origen y apoyo de la danza sino también un sistema autogenerado de signos funcionales, operativos. Langer le concede, por tanto, cualidades simbólicas intrínsecas dado que el gesto "es siempre también espontáneamente expresivo por virtud de su forma ..." 190 sea, en esta generalización por fuerza tendríamos que eludir el gesto "contradictorio" instintivo, el gesto de personas afectadas cerebralmente o bien aquel que responda a estados psicológicos de tipo patológico.

Haciendo caso omiso del hecho de que la gesticulación podria muy bien contener las mismas aptitudes "naturalmente" expresivas del gesto, creemos que se hace de lado una situación fundamental: la especificidad de los signos de la "danza como expresión" no anula la posibilidad de los signos-manifestaciones de una configuración internalizada (sistema). Si Mary Wigman afirmó que aborrecia "todo gesto sin sentido", no creo, como lo cree Langer, que expusiera "una contradicción en los términos". No puede apoyarse toda una teoría de la danza en la "radicalización" de un concepto, forzando la inclusión de ideas contrarias a las expresadas por los especialistas. En términos de la realidad cotidiana, espontánea, sabemos que tanto el gesto como la gesticulación (como la danza misma) son elementos, acciones que pueden representar la existencia de un código, de un sistema de signos asimétricos de la "expresividad" normal o aceptada. De otra manera, la interpretación de ellos significaría, ya, uno más de los medios de que se valen los seres humanos para comunicarse "culturalmente". Sin embargo, el propio Cassirer, a quien Langer sigue fundamentalmente en lo que respecta al estudio de las formas simbólicas, ha explicado la necesidad de:

Eliminar este velo... [de] "penetrar en la esfera originaria de la visión intuitiva retrotrayéndonos desde la esfera mediadora del mero significar y designar" ... ${ }^{20}$ [pues] todo lo que [la cultura] crea en su proceso siempre progresivo de configuración y "forma" nos aleja más y más de la originalidad de la vida. ${ }^{21}$

18 Susan K. Langer, p. 7.

18 Susan K. Langer, p. 8.

20 Ernst Cassirer, p. 60.

21 Ernst Cassirer, p. 59. 


\section{Lenguaje y capacidad de movimiento}

\section{Lo móvil inexpresivo}

El hombre realiza multitud de movimientos durante sus actividades de la vida diaria que en nada se relacionan con la expresión consciente ni con el autoconocimiento del cuerpo. Estas acciones están impuestas por la realidad y no necesariamente implican una "comunicación" codificada con el medio ambiente o con los demás miembros del grupo. La experiencia de realizar movimientos inexpresivos conlleva, sin embargo, una especie de posible código que se refiere a la internalización y adaptación de ciertos, peculiares movimientos que es obligatorio que el hombre realice en el trabajo, en las diversiones e incluso en actividades aisladas: comer, bañarse, fumar, sentarse, acostarse, etcétera. En la respuesta del cuerpo a estas actividades necesarias se halla, pues, el núcleo de un sistema de signos que han perdurado a través del tiempo y que se repiten de generación en generación sin alterarse. Algunos de estos signos internalizados no han sido asimilados por la "danza como expresión", aunque en ocasiones algunos creadores manifiesten una tendencia a ir hacia ellos y manipularlos como "expresiones". No nos referimos a la "naturalidad" de ciertos movimientos utilizados, por ejemplo, por Cunningham o Nikolais, sino a la desimbolización consciente que precede al acto creativo de muy contados artistas contemporáneos (intentos de Falco, "inferiorizaciones" de algunas formas artísticas, desacralización). Lo móvil inexpresivo precede a la acción dancística en la medida en que "destempla" a la anécdota, en la medida en que (sin establecer una ruptura) concibe al movimiento como una acción inexpresiva, sin funcionalidad ni significación. En ese caso se hallarían, por ejemplo, algunos movimientos imprescindibles pero desvinculados al "hecho" concreto, verbigracia, los movimientos que debe realizar un cuerpo humano para permanecer a flote en un tanque de agua: desprovistos de la idea de "natación" o de la natural animalidad de la supervivencia, devendrían movimientos-abstracciones que sin duda poseen parámetros precisos: no hay múltiples variaciones, pues el cuerpo, por su configuración, responde, para flotar, mediante la acción precisa de sus miembros. Otro ejemplo: las reacciones móviles de un cuerpo acribillado por balas accidentales. ¿Cuál expresión, cuál significación puede percibirse en esos miembros que actúan por mero instinto para defenderse de lo inde- 
fendible, de lo inaplazable? Lo móvil inexpresivo, en este sentido, ha permanecido, sobrevivido hasta la época contemporánea al margen de las expresiones o simbolizaciones inventadas o descubiertas por la danza, durante varios siglos, y sus parámetros (codificables aun en la época actual) significan una veta inexplorada hasta la fecha.

A lo largo del presente siglo, la danza moderna parece impelida en dirección del descubrimiento de lo móvil inexpresivo para asimilarlo a la codificación (universal) que sus artistas y creadores tratan de configurar y organizar. En sus iniciales planteamientos, Isadora Duncan sólo intentaba hacer más naturales y espontáneas las formas aparentes de la danza. Tal vez "sintió", en su búsqueda de formas más directas y puras, que el cuerpo mismo exigía llevar las prácticas e investigaciones del "nuevo arte" hasta sus últimas consecuencias, pero su noción romántica, desproporcionada y exagerada de "belleza", "luz", etcétera, la obligaron a detenerse en una "forma" dancística bastante superficial y hasta deshumanizada desde el punto de vista biológico, pues sólo un afán de perfección puede impulsar hacia el interior del cuerpo ese elemento "superior" que hace arte del movimiento:

En el cuerpo armónicamente desarrollado y llevado a su punto supremo de energía, penetra el espíritu de la danza. Para el gimnasta, el movimiento y la cultura del cuerpo son un fin en si, pero para el bailarín no son sino medios. El mismo cuerpo debe ser olvidado; es únicamente un instrumento armónico y bien apropiado, y sus movimientos no sólo expresan, como en la gimnasia, movimientos corporales, sino sentimientos y pensamientos del alma. ${ }^{22}$

Considerar, interpretar la danza como creación, como conjunto de acciones impregnadas de símbolos, como reunión de significaciones, de expresiones, exige hacer caso omiso de la danza como lenguaje. Otros creadores posteriores a Isadora también llegaron a percibir la necesidad de descubrir lo móvil-inexpresivo, pero como ella se detuvieron en el punto de inflexión, en el justo límite de la danza como expresión Atribuyéndole una naturaleza eminentemente simbólica, Mary Wigman considera que si la acción del bailarín es:

Una predestinación para crear, entonces [las creaciones dancísticas] no tenderán a ser, y no pueden ser, sino una confesión de vida lleva-

22 Isadora Duncan, p. 147. 
da a la forma simbólica. Constituirán la aceptación de decir "si" a todo lo que está vivo y que produce vida. ${ }^{23}$

Como puede apreciarse, las nociones de Wigman en torno a la danza se detienen en la forma simbólica pero vislumbran algunos elementos que van más allá o sencillamente se encuentran más cerca de las acciones vitales que de las acciones simbólicas. A diferencia de Isadora Duncan, Wigman aprecia intuitivamente la inclusión en la danza de manifestaciones internas, cuyo origen subyace en la acción o impulso del movimiento. Sin embargo, Wigman considera que sólo una vez expresados mediante el acto dancístico, los "deseos pasionales", aun sin poder quedar expresados plenamente en un título o mediante un término profesional, pueden ser descritos "en su vinculación a una [capacidad de] conciencia de vida", ${ }^{24}$ ya que "arte es la comunicación que el hombre expresa para la humanidad en un lenguaje que surge desde los sucesos cotidianos". ${ }^{25}$ La idea fundamental de Wigman permaneció dentro del ámbito de la danza como expresión, a pesar de que, como Duncan, percibió la necesidad de ir a encontrar el código básico de la danza como lenguaje. La clave de la resistencia de Wigman a profundizar al respecto se halla en la explicación de Arthur Michel sobre el sistema Wigman, la cual parece "sobrevolar" la danza como lenguaje cuando lógicamente debería explicarla. El texto dice así:

La habilidad que el bailarín adquiere no es una mecánica gramática del movimiento sino la capacidad de transformar cada uno de sus innumerables impulsos en una tensión espacial productiva que queda descargada orgánicamente en la forma dancística. De esta manera, la danza se hace una función del deseo que siente el bailarín de expresarse... ${ }^{26}$

La danza queda así considerada en términos de impulsos individuales (no universales), en términos de expresiones de un ente, el bailarín, que mediante el entretenimiento y el autoconocimiento del cuerpo y sus capacidades se ha convertido en creador. Si Wigman hubiese llevado hasta sus últimas consecuencias sus investigaciones sobre los impulsos del cuerpo (tal como lo hizo con relación a, por ejemplo, sus concep-

23 Mary Wigman, p. 19.

24 Mary Wigman, p. 19.

25 Mary Wigman, p. 21.

26 Arthur Michel, p. 3. 
tos del espacio), hubiera arribado de manera natural a la danza como lenguaje. Rudolph Von Laban, su maestro, ya había encauzado a Wigman en esta dirección, pues él:

Reconoció las vinculaciones legítimas entre la estructura del cuerpo humano y su capacidad de dirección y movimiento. Aunque diferentes en sus resultados, las leyes del movimiento son las mismas que aquellas que gobiernan la vida cotidiana en el trabajo, el deporte, la danza o la gimnasia... ${ }^{27}$

\section{Lo inmóvil expresivo}

Las simultáneas o posteriores reflexiones de las otras creadoras de la danza moderna coincidieron con el sentido que Mary Wigman impuso a sus búsquedas. Doris Humphrey se inquietó por una definición de danza que concebía al movimiento como un "arco entre dos muertes", c sea como una acción ineludible, ya que nadie puede permanecer en uno de los extremos. Asimismo, la danza puede ser concebida emocionalmente, pero debe construirse intelectualmente, de modo que si al estudiante de danza debe otorgársele la posibilidad de situar un énfasis inicial en la sensación o el sentimiento, se trata tan sólo de un medio para tender un puente hacia la comprensión y el control cabales de su propio cuerpo. ${ }^{28}$ De igual manera, las ideas y reflexiones de Charles Weidman sobre el "sexo" de la danza y sobre la pantomima, así como el enorme desarrollo técnico logrado por Martha Graham mediante la ubicación del centro de impulsos del movimiento para las acciones del bailarín, convergieron hacia la configuración de un concepto de danza que no se apartó de la danza como expresión. Salvo contadísimas excepciones (y todas ellas experimentales, no teóricas), ninguna de las actuales tendencias de la danza contemporánea contempla el estudio de la danza como lenguaje. La caracterización de la escuela más plenamente desarrollada hasta la fecha (la de Martha Graham) como un nuevo academismo no se halla lejos de la verdad. La definición que Harald Kreutzberg expusiera para la danza moderna ${ }^{29}$

27 Arthur Michel, p. 5 (el subrayado es nuestro).

28 Doris Humphrey y Paul Love, p. 59.

29 "La danza moderna es un fenómeno estilístico-específico, análogo a la aparición del expresionismo en pintura. Tiene como objetivo el abandono de ciertas leyes técnicas en favor de una comunicación más francamente emocional y atmosférica." Harald Krutzberg, p. 31 . 
podria quedar completa mediante la inclusión, al final, de la siguiente frase: "Esta comunicación ha descubierto y conformado sus propias leyes técnicas."

La extremada tendencia de la danza contemporánea hacia la expresión simbólica aparta a los experimentos de hoy del lenguaje original, de aquellos factores y movimientos iniciales que persisten en las formas y acciones más primitivas y antiguas del cuerpo humano. En este alejamiento parecen alejarse también las posibilidades de codificación de una actividad de alcances universales. $\mathrm{Si}$, como plantea Cassirer:

Desde el punto de vista objetivo [el sonido y por tanto el lenguaje discursivo] se vuelve apto para servir, no sólo para expresar cualidades materiales, sino ante todo para expresar relaciones y determinaciones. formales de relación... ${ }^{30}$

habrá que regresar al estudio del punto, del momento en el que la danza perdió la oportunidad de erigirse en lenguaje codificado para que el hombre se comunicara espacialmente sin las limitaciones e inventivas del simbolismo y el arte, para que se comunicara mediante un "lenguaje otro" que, poseedor de las necesarias significaciones, permite a los hombres, al grupo utilizar el cuerpo humano como materia prima "civilizada", culturizada. La suerte de este lenguaje oculto, no aplicado conscientemente, dependerá de las investigaciones serias que se realicen en este sentido y de la adaptación de ellas a una nueva técnica que conciba a la danza como un lenguaje anterior a las formaciones simbólicas que dieran vida al arte-danza. Muchos elementos de este tipo se hallan ya a la vista, embrionariamente, en ciertos ejercicios, prácticas e incursiones de los grupos actuales de danza contemporánea. Mediante una técnica nueva, estructurada en base a estos conocimientos, tal vez la danza contemporánea amplie su radio de acción y penetre definitivamente en nuevos universos y formas.

30 Ernst Cassirer, p. 142.

\section{BIBLIOGRAFIA}

Cassirer, Ernst: Filosofia de las formas simbólicas, 3 tomos, México, Fondo de Cultura Económica, 1971, 310 pp., 320 pp., 555 pp. La paginación del ensayo se refiere al tomo I. 
Dallal, Alberto: “Cuerpo y abstracción", en Gozosa revolución, México, UNAM, 1973. 233 pp. (Se reproduce en este libro.)

Duncan, Isadora: $M i$ vida, Buenos Aires, Editorial Losada, 1973. 295 Pp.

Humphrey, Doris y Love, Paul, "The Dance of Doris Humphrey". en Stewart, Virginia y Armitage, Merle, The Modern Dance, New York, Dance Horizons, 1970. 107 pp.

Jung, C. G.: Simbolos de transformación, Buenos Aires, Editorial Paidós, 1962. 441 pp.

Kreutzberg, Harald: "The Modern Dance", en Stewart, Virginia, y Armitage, Merle: The Modern Dance. New York, Dance Horizons, 1970. 107 pp.

LANGer, Susan K.: Sentimiento y forma, México, Centro de Estudios Filosóficos, UNAM, 1967. 405 pp.

Michel, Arthur: "The Development of the New German Dance", en Stewar, Virginia y Artimage, Merle: The Modern Dance, New York, Dance Horizons, 1970. 107 pp.

Paz, Octavio: El mono gramático, Seix Barral, Biblioteca Breve, 1975. 142 pp.

Wigman, Mary: "The New German Dance", en Stewart, Virginia y Armitage, Merle: The Modern Dance. New York, Dance Horizons, 1970. 107 pp.

SAcHs, Curt: World History of the Dance. The Norton Library, New York, 1963. 460 pp. 